\title{
Security of a Selected Building Using KARS Method
}

\author{
KRISTINA BENESOVA, PETR SVOBODA, JAKUB RAK, VACLAV LOSEK
}

\author{
Tomas Bata University in Zlin, nam. T. G. Masaryka 5555 \\ 76001 Zlin Czech Republic \\ k2_benesova@utb.cz,psvoboda@utb.cz,jrak@utb.cz, losek@utb.cz
}

\begin{abstract}
This article is focused on securing a building that has been selected in the Czech Republic. The aim of the thesis is to analyze risks and propose security measures. The first part of the article introduces security issues with a special focus on intrusion detectors, fire detection and fire-alarm systems, and last but not least electronic security systems. Furthermore, it deals with the characteristics of the building and a subsequent analysis using the KARS method. The measures proposed are referred to in the conclusion for improving the current situation. The results of the research allow for the implementation of the proposals into practice.
\end{abstract}

Key-Words: -. analysis, detector, security, security systems.

\section{Introduction}

In recent years, society has been experiencing property crimes with an ever increasing tendency. Therefore, no one can be surprised that society is increasingly improving security not only in connection with its health but also its property. Although Act No. 110/1998 Sb., on the Security of the Czech Republic, guarantees its citizens security, it can be observed that there is an increasing interest in security on the part of the subjects themselves. Through risk analysis this student's scientific activity will propose measures, which will lead to an increase of protection for the selected building.

Prior to the risk analysis and any proposed measures of protection it is necessary to familiarise ourselves with devices which will be discussed later on.

An intrusion detector is a device designed to generate a signal or intrusion report in response to an abnormal state detecting the presence of danger. $[1,2]$

Intrusion detectors can be divided according to several criteria. The first criterion is whether they are powered (passive and active) or non-powered (destructive and non-destructive).

Furthermore, the detectors are divided according to the type of protection they provide within their location and direction; the types of protection include perimeter, external, spatial protection and the protection of objects. A further classification is based on the physical signal used; the detectors can be electromechanical, electromagnetic and electroacoustic.
The intrusion detector should be resistant against unauthorized access to its components and settings, against removal from the fixture, resistant to the change of orientation, and it has to be sensitive to disturbance by magnetic fields. $[1,2,3]$

Alarm security systems and emergency systems inform about unwanted intrusion into the building. These devices are inherently ineffective if the information is not passed on early enough to designated individuals. Within this field there have been constant innovations and developments related to communicators, control peripherals, smart wiring and last but not least, the area of active protection. The end-points of these systems are central dispatching stations or surveillance and alarm reception centres in which a person receives a signal from a device and then sends out an authorized person. [1,2]

In order to fulfil the basic functions of a fire alarm system (FAS), the FAS control panel and the fire alarm are connected and create a signalling line circuit loop; the requirements for the individual components can be found in a Standard that specifies the technical requirements. $[2,4]$

Mechanical barriers are all means that are used to protect against forced entry by persons; their task is to impede the perpetrator as much as possible. This group includes, for example, security doors, iron bars or window protectors to prevent or hinder access to the building. [2,5] 


\section{Characterictics of the selected building}

The selected building is located in a village with extended powers; it is a ground-floor family house, which is inhabited by only two people. The building is secured by basic elements for perimeter protection. It is defined by the registered boundary and the protective elements must have high climatic resistance. Then there is the external protection which is implemented on the exterior of the protected building, i.e. walls, doors, windows, locks, locking systems, bars, security foils, camera systems and intrusion detectors.

\subsection{The KARS method}

The qualitative method of risk analysis with risk correlations was used for the correct evaluation of the appropriate security elements. The highest possible risk is obtained by means of this method and this will lead to a proposal of measures for the given building.

The first step was to compile a list that contained possible sources of risks for the building. In total, ten types of risk were selected within the probability of possible danger. The resulting risks can be seen in Table 1.

Creating the table of risks is another important phase of the KARS analysis. The first column contains selected types of risks for the building, which are numbered 1 to 10 while the first row of the table contains individual numbers of types of risks.

The actual method is based on the interaction and correlation of individual types of risks. For proper compliance with the procedure, the table must be filled in as follows:

- 1 - is filled in if $R_{i}$ can cause risk $R_{j}$.

- 0 - is filled in if $R_{i}$ cannot cause risk $R_{j}$. $[2,6]$

\begin{tabular}{|c|c|c|c|c|c|c|c|c|c|c|c|}
\hline Risk & 1 & 2 & 3 & 4 & 5 & 6 & 7 & 8 & 9 & 10 & Total \\
\hline $\begin{array}{l}\text { 1. Breaking the } \\
\text { window }\end{array}$ & $\mathbf{0}$ & 1 & 0 & 1 & 0 & 0 & 0 & 0 & 0 & 0 & 2 \\
\hline 2. Break-in & 1 & $\mathbf{0}$ & 1 & 1 & 1 & 1 & 1 & 1 & 0 & 1 & 8 \\
\hline 3. Fire & 1 & 0 & $\mathbf{0}$ & 1 & 1 & 1 & 0 & 1 & 0 & 1 & 6 \\
\hline $\begin{array}{l}\text { 4. Failure of } \\
\text { mechanical } \\
\text { systems }\end{array}$ & 0 & 1 & 0 & $\mathbf{0}$ & 1 & 0 & 0 & 0 & 0 & 1 & 3 \\
\hline 5. Power failure & 0 & 1 & 0 & 1 & $\mathbf{0}$ & 0 & 0 & 0 & 0 & 1 & 3 \\
\hline $\begin{array}{l}\text { 6. Damage to the } \\
\text { facade }\end{array}$ & 0 & 0 & 0 & 0 & 0 & o & 0 & 0 & 0 & 0 & 0 \\
\hline 7. Cyber-attack & 0 & 1 & 0 & 1 & 1 & 0 & $\mathbf{0}$ & 0 & 0 & 1 & 4 \\
\hline 8. Explosion & 1 & 0 & 1 & 1 & 1 & 1 & 0 & $\mathbf{0}$ & 0 & 1 & 6 \\
\hline 9. Flood & 0 & 1 & 0 & 1 & 1 & 1 & 0 & 0 & $\mathbf{0}$ & 1 & 5 \\
\hline 10. FAS failure & 0 & 1 & 0 & 1 & 0 & 0 & 0 & 0 & 0 & $\mathbf{0}$ & 2 \\
\hline Total & 3 & 6 & 2 & 8 & 6 & 4 & 1 & 2 & 0 & 7 & \\
\hline
\end{tabular}

Table 1. Risk correlation table

\subsection{Calculations of activity and passivity coefficients}

For the risk qualification the activity and passivity coefficients were used. By means of these coefficients, the resulting table of correlations was transformed into a mathematical form and after that to a graphical form.

- $\mathrm{K}_{\mathrm{ARi}}$ - the activity coefficient - represents a percentage of the number of selected types of risks that are linked to the risk marked as $\mathrm{R}_{\mathrm{i}}$. In case that risk $\mathrm{R}_{\mathrm{i}}$ occurs, the consequential risks can be triggered.

- $\mathrm{K}_{\mathrm{PRi}}$ - the passivity coefficient - represents a percentage of the number of selected types of risks, which are linked to the risk marked as $R_{i}$ and which may subsequently trigger the risk $R_{i}$. 
In ordered to express the activity and passivity coefficients it was necessary to put together a number of combinations. Provided that risk $R_{i}$ cannot induce itself, or risk $R_{i}$ can induce other types of risks, or it can be induced by other types of risks it holds that $\mathrm{x}=10$. In this case, the number of possible combinations is $\mathrm{x}-1$. $[2,6]$

\section{Calculation of the activity coefficient $K_{A R i}$ for individual risks $\mathbf{R}_{\mathbf{i}}$ :}

$$
\begin{aligned}
& \mathrm{K}_{\text {, }}-\frac{\sum \mathrm{Ri}}{\mathrm{x}-1}, 100[\%] \\
& \text { 1. } K_{A R I}=\frac{\sum_{R i}}{x-1} \cdot 100[\%]=\frac{2}{10-1} \cdot 100=\frac{2}{9} \cdot 100=22,22 \% \\
& \text { 2. } K_{\text {ARi }}=\frac{\sum_{R i}}{\pi-1} \cdot 100[\%]=\frac{8}{10-1} \cdot 100=\frac{8}{9} \cdot 100=88,88 \% \\
& \text { 3. } K_{A R i}=\frac{\sum R i}{x-1} \cdot 100[\%]=\frac{6}{10-1} \cdot 100=\frac{6}{9} \cdot 100=66,66 \% \\
& \text { 4. } K_{A R i}=\frac{\sum R i}{x-1} \cdot 100[\%]=\frac{3}{10-1} \cdot 100=\frac{3}{9} \cdot 100=33,33 \% \\
& \text { 5. } K_{A R i}=\frac{\sum R i}{x-1} \cdot 100[\%]=\frac{3}{10-1} \cdot 100=\frac{3}{9} \cdot 100=33,33 \% \\
& \text { 6. } \mathrm{K}_{\mathrm{ARi}}=\frac{\sum_{\mathrm{Ri}}}{\mathrm{x}-1} \cdot 100[\%]=\frac{0}{10-1} \cdot 100=\frac{0}{9} \cdot 100=0 \% \\
& \text { 7. } K_{\text {ARI }}=\frac{\sum_{R i}}{x-1} \cdot 100[\%]=\frac{4}{10-1} \cdot 100=\frac{4}{9} \cdot 100=44,44 \% \\
& \text { 8. } K_{A R I}=\frac{\sum_{R i}}{x-1} \cdot 100[\%]=\frac{6}{10-1} \cdot 100=\frac{6}{9} \cdot 100=66,66 \% \\
& \text { 9. } K_{A R I}=\frac{\sum_{R i}}{x-1} \cdot 100[\%]=\frac{5}{10-1} \cdot 100=\frac{5}{9} \cdot 100=55,55 \% \\
& 10 . K_{A R i}=\frac{\sum R i}{x-1} \cdot 100[\%]=\frac{z}{10-1} \cdot 100=\frac{2}{9} \cdot 100=22,22 \%
\end{aligned}
$$

Calculation of the passivity coefficient KPRi for individual risks $R_{\mathbf{i}}$ :

$$
\begin{aligned}
& K_{90}-\frac{2 R i}{x-1}, 100[9] \\
& \text { 1. } \mathrm{K}_{\mathrm{DRi}}=\frac{\sum \mathrm{Ri}}{x-1} \cdot 100[\%]=\frac{3}{10-1} \cdot 100=\frac{3}{9} \cdot 100=33,33 \% \\
& \text { 2. } K_{\mathrm{DRi}}=\frac{\sum R i}{x-1} \cdot 100[\%]=\frac{6}{10-1} \cdot 100=\frac{6}{9} \cdot 100=66,66 \% \\
& \text { 3. } K_{\mathrm{DRi}}=\frac{\sum \mathrm{Ri}}{x-1} \cdot 100[\%]=\frac{2}{10-1} \cdot 100=\frac{2}{9} \cdot 100=22,22 \% \\
& \text { 4. } \mathrm{K}_{\mathrm{DRi}}=\frac{\sum_{\mathrm{Ri}}}{\mathrm{x}-1} \cdot 100[\%]=\frac{8}{10-1} \cdot 100=\frac{8}{9} \cdot 100=88,88 \% \\
& \text { 5. } K_{\mathrm{DRi}}=\frac{\sum_{\mathrm{Ri}}}{x-1}, 100[\%]=\frac{6}{10-1} \cdot 100=\frac{6}{9} \cdot 100=66,66 \% \\
& \text { 6. } K_{\mathrm{DRi}}=\frac{\sum_{\mathrm{Ri}}}{x-1}, 100[\%]=\frac{4}{10-1} \cdot 100=\frac{4}{9} \cdot 100=44,44 \% \\
& \text { 7. } K_{\mathrm{DRi}}=\frac{\sum_{\mathrm{Ri}}}{\mathrm{x}-1} \cdot 100[\%]=\frac{1}{10-1} \cdot 100=\frac{1}{9} \cdot 100=11,11 \% \\
& \text { 8. } K_{\mathrm{DRi}}=\frac{\sum \mathrm{Ri}}{x-1} \cdot 100[\%]=\frac{2}{10-1} \cdot 100=\frac{2}{9} \cdot 100=22,22 \% \\
& \text { 9. } K_{\text {DRi }}=\frac{\sum_{R i}}{x-1} \cdot 100[\%]=\frac{0}{10-1} \cdot 100=\frac{0}{9} \cdot 100=0 \% \\
& 10 . K_{\mathrm{DRi}}=\frac{\sum_{\mathrm{Ri}}}{x-1} \cdot 100[\%]=\frac{7}{10-1} \cdot 100=\frac{7}{9} \cdot 100=77,77 \%
\end{aligned}
$$

\subsection{The resulting correlation chart}

The objective of the chart is to determine the significance of all risks and their correlations in the system. The chart is divided into 4 categories using the axes $\mathrm{O} 1$ and $\mathrm{O} 2$ :

I. Primary and secondary hazardous risks.

II. Secondary hazardous risks.

III. Primary hazardous risks.

IV. Relatively safe sphere. [2,5]

Sphere I covers $80 \%$ of the total area in which the evaluated risks are found. It holds for the axis $\mathrm{O}_{1}$ that:

$$
\mathrm{K}_{\mathrm{Amax}}-\mathrm{K}_{\mathrm{Amin}}=100 \%
$$

Under the condition of $80 \%$, the axis $\mathrm{O}_{1}$ will be parallel to the axis y at a distance of: [7]

$$
\begin{gathered}
\mathrm{O}_{1}=\mathrm{K}_{\mathrm{Amax}}-\frac{\mathrm{K}_{\mathrm{Amax}}-\mathrm{K}_{\mathrm{Amin}}}{100} .80 \\
\mathrm{O}_{1}=88,88-\frac{88,88-0}{\stackrel{100}{100} .80=88,88-71,04} \\
=17,84
\end{gathered}
$$

The result for $\mathrm{O}_{1}=17,84 \%$ 
Under the condition of $80 \%$, the axis $\mathrm{O}_{2}$ will be parallel to the axis $x$ at a distance of:

$$
\begin{gathered}
\mathrm{O}_{2}=\mathrm{K}_{\mathrm{Pmax}}-\frac{\mathrm{K}_{\mathrm{Pmax}}-\mathrm{K}_{\mathrm{Pmin}}}{100} .80 \\
\mathrm{O}_{2}=88,8-\frac{88,8-0}{100} .80=88,8-71,04 \\
=17,84
\end{gathered}
$$

\section{The result for $\mathrm{O}_{2}=17,84 \%$}

\subsection{Evaluation of the KARS method}

The resulting correlation chart aims to determine the significance of all types of risks and their correlation in the system. Evaluation of the KARS method:

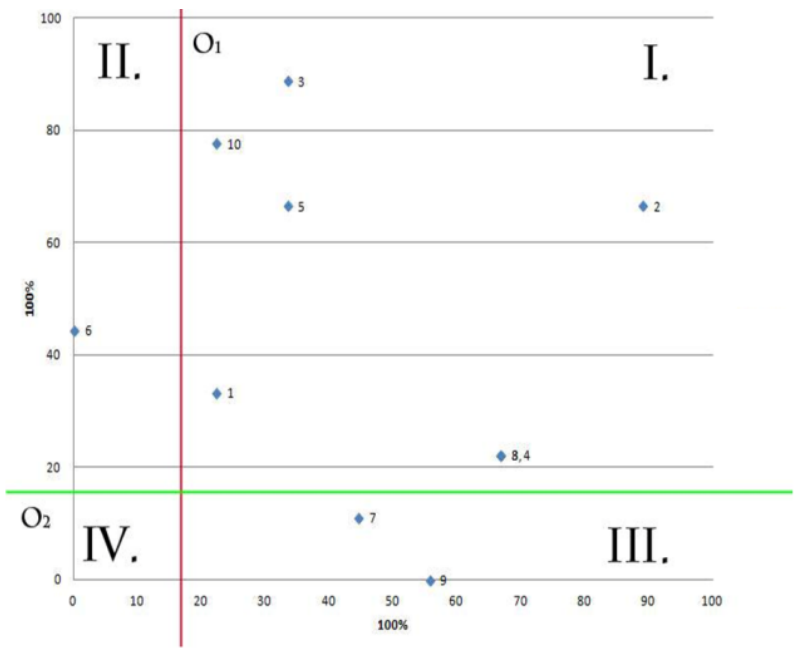

Fig. 1. Evaluation of the KARS method

Sphere I: Primary and secondary hazardous risks risks -1 (breaking the window), 2 (break-in), 3 (fire), 4 (failure of mechanical devices), 5 (power failure), 8 (explosion), 10 (FAS failure).

Sphere II and III: Primary and secondary hazardous risks - risks - 6 (damage to the facade of the building), 7 (cyber-attack), 9 (flood).

Sphere IV: Relatively safe - no risks detected. [2,6]

\section{Proposed measures}

The proposal for risk reduction is a conceptual solution for the implementation of individual protective measures. Owing to the established measures, the likelihood of vulnerability of the building and the assets should be reduced. Based on the risk analysis performed by means of the KARS method, the greatest and most probable risks are breaking the window, break-in, fire, failure of mechanical devices, power failure, explosion, and FAS failure. Measures will be taken to improve the current situation for these risks.

The "PerimetrLocator" (Perimeter Locator System) using RFID - Radio-Frequency Identification tags has been chosen for the protection of the perimeter. The system is to be placed onto the surrounding fence; the advantage of this is that it eliminates false alarms, which is highly desirable. Detectors that are built into the ground were excluded due to their frequent false alarms. As a last resort, differential pressure detectors could also be considered. They are intended for the protection of the perimeter of the guarded area. The detector is capable of sensing motion up to $100 \mathrm{~m}$ away and it can be used even in very rugged terrains. Since the detectors are hidden underground, it is difficult for intruders to discover them. The disadvantage, however, is that they are sensitive to movement of tree and shrub roots.

The external protection of the building can be provided by a security door and wireless glass break detectors located above a window in a room; these detectors are necessary because windows are the main weak points of the building. They are used to protect larger glass surfaces. The passive sensor evaluates breaking and shattering of glass, a shock wave spreading along the surface of a pane of glass, and a sound pressure wave spreading into the space when the pane of glass is broken. On the contrary, the active sensor evaluates ultrasound waves and electromagnetic infrared waves.

Spatial protection will be covered by an alarm security system and an emergency system without a fingerprint reader; instead, a remote control that is much more practical for the building is to be used. In addition, a passive infrared sensor will be located in every room. This sensor evaluates changes in the infrared spectrum of the electromagnetic waves. It is one of the most widespread types of motion detectors designed for perimeter protection. Undoubtedly, its advantage is its ease of installation and low power consumption. Its disadvantage, however, is the possibility of interference, for example, by car lights or direct sunlight. It consists of the following basic parts:

- Infrared sensor.

- Optical system.

- Electronics for processing of the detected signal.

- Locking element for detecting unwanted manipulation.

- LED indicators for indicating the status of the detector. 
- Additional circuits.

The electromagnetic detectors also include infrared barriers, microwave detectors, radio barriers and detectors, capacitive detectors and laser detectors. $[2,3]$

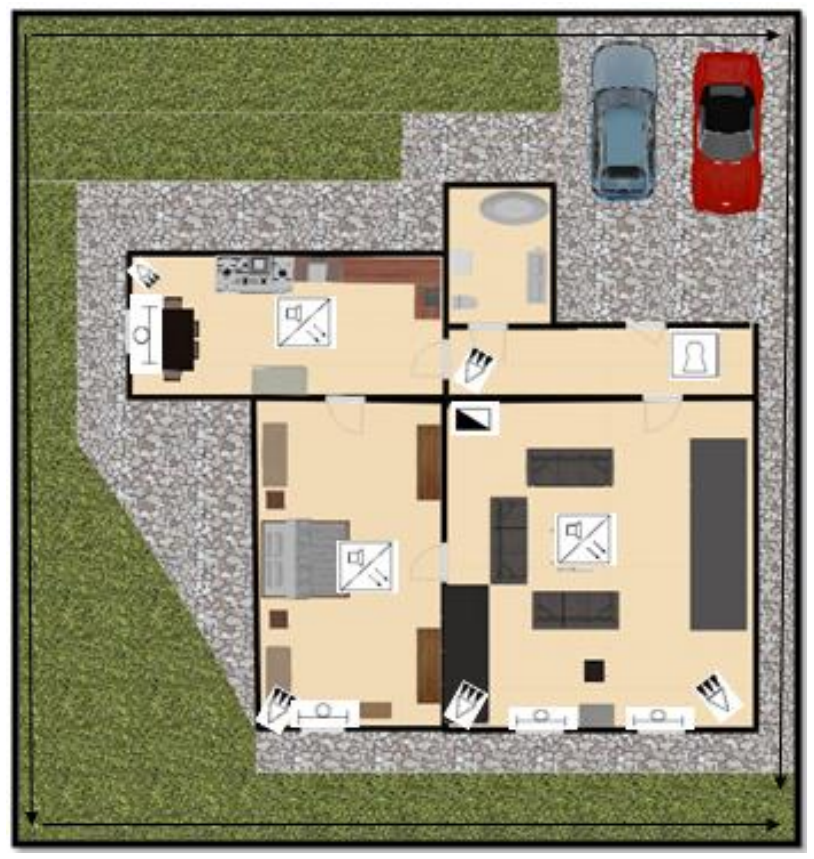

Fig.2 Proposal of measures.

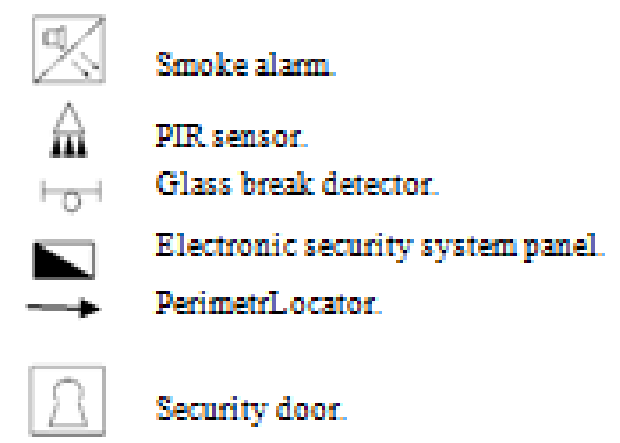

\section{Conclusion}

The protection of health, property, social and other values has safeguarded humanity from the beginning time. However, in recent years, the market has come up with several innovations based on existing systems, as well as the fact that it contributes to a better way to protect these values. Securing property is often a very daunting problem. A critical factor is, above all, ensuring the integrity of security systems or making the correct choice of security systems. There are individuals who are still unaware of the seriousness of the risks that we are threatened with but which can be avoided.
This article dealt with the security of the selected building, in this case a family house. At the beginning, the concepts that appeared in the followup part of the article and which were necessary for understanding the given issues were emphasized. This was followed by the description of the selected building and its current security features. Furthermore, a qualitative risk analysis was carried out using the correlation of risks by means of the KARS method.

Within the analysis it was important to create a list of ten risks related to the security of the given building. Upon the creation of the list, a table of risks was created to which numbers 1 or 0 were assigned. The next step included calculations of the activity and passivity. Based on these calculations, the resulting correlation chart was created. The chart of correlations has identified primary and secondary risks such as breaking windows, burglary, fire, failure of mechanical devices, power failure, explosion, FAS failure.

The proposal for risk mitigation is a conceptual solution for the implementation of the individual measures. Due to the measures taken, the likelihood of vulnerability of the object and of the assets themselves should be reduced. In conclusion and from the outcome of the work, besides the evaluation of the risk analysis in the form of the proposed measures, there is also a model with the implementation of the individual proposals leading to the reduction of the risks. The analysis has served for proposing measures that would improve the current security of the building.

Acknowledgments: This paper is supported by the Internal Grant Agency at Tomas Bata University in Zlin, projects No. IGA/FLKR/2017/003, No. IGA/FLKR/2018/001.

\section{References:}

[1] LUKÁŠS, Luděk, 2015. Bezpečnostni technologie, systémy a management. (Security technologies, systems and management.) Zlín: Radim Bačuvčík - VeRBuM. ISBN 978-8087500-05-7.

[2] Applied Physics, System Science and Computers III: Proceedings of the 3nd International Conference on Applied Physics, Systém Science and Computers (APSAC2018), September 25-28, 2018, Dubrovnik, Croatia, 2018. Springer. ISSN 978-3-319-75605-9

[3] ČSN EN 50131-2-2. Detektory narušení Pasivní infračervené detektory. (Technical Standard ČSN EN 50131-2-2. Intrusion 
detectors - Passive infrared sensors.) Prague: Český normalizační institut, 2008.

[4] BEBČÁK, Petr, 2004. Požárně bezpečnostní zařizení. (Fire safety equipment.) $2^{\text {nd }}$ extended edition. Ostrava: Sdružení požárního a bezpečnostního inženýrství. (Fire and Security Association.) Spektrum (Sdružení požárního a bezpečnostního inženýrství). ISBN 80-8663434-5.

[5] IVANKA, Ján. Mechanické zábranné systémy. (Mechanical barrier systems.) Zlín: Tomas Bata University in Zlin, 2010, 151 p. ISBN 978-80-7318-910-5.

[6] SÍŤOVÁ ANALÝZA A METODA KARS. (NETWORK ANALYSIS AND THE KARS METHOD.) [online], 2010. (1) [cit. 2018-04-08]. Available at: http://www.populationprotection.eu/prilohy/casopis/8/56.pdf. 